\title{
Using a laptop computer for work: musculoskeletal disorders and the functional characteristics of the neck in comparison with the users of desktop computers
}

\author{
Martin Argus ( $\nabla$ martin.argus@ut.ee) \\ University of Tartu \\ Mati Pääsuke \\ University of Tartu
}

\section{Research Article}

Keywords: laptop, desktop, musculoskeletal disorders, musculoskeletal pain, neck, range of motion, strength, joint position error, pain-pressure threshold

Posted Date: July 8th, 2021

DOI: https://doi.org/10.21203/rs.3.rs-677027/v1

License: (9) This work is licensed under a Creative Commons Attribution 4.0 International License.

Read Full License 


\section{Abstract \\ Background}

Using a laptop for work is gaining rapid popularity, but there is little evidence of how it influences musculoskeletal disorders (MSD) and functional characteristics of the neck and shoulder area. The aim of this study was to compare the prevalence of upper body MSDs and functional characteristics of the neck between office workers using a laptop or desktop computer.

\section{Methods}

A total of 110 office workers with a mean age of $41 \pm 10$ participated. From them 45 office workers (73\% female) used a laptop and 65 office workers ( $86 \%$ female) desktop computers. The prevalence of MSDs was recorded using the Nordic Musculoskeletal Questionnaire. Active range of motion (AROM), maximal voluntary isometric contraction (MVC) force, joint position error (JPE), and pain-pressure threshold (PPT) of the neck were measured.

\section{Results}

Laptop users had statistically significantly more MSDs in the right shoulder area on the day of participation $(p<0.001, O R=4.47)$, during the previous 7 days $(p<0.01, O R=3.74)$ and 6 months $(p<$ $0.01, \mathrm{OR}=3.57)$. Laptop users had also significantly more MSDs in the left shoulder during the previous 7 days $(p<0.05, O R=2.44)$. Desktop computer users had more MSDs in the low back during the previous 6 months $(p<0.05, O R=2.24)$. There were no statistically significant differences in any of the functional characteristics of the neck between the groups.

\section{Conclusions}

Using the laptop computer for office work can cause a higher chance of developing MSDs in the neck and shoulder area, but might not have a long-term effect on the functional characteristics of the neck.

\section{Introduction}

Laptop computers are gaining popularity in several areas like office work and education. The main reasons behind the increasing usage of laptops are portability, low weight, affordable prices, wireless access, and connectivity. For these reasons, the advantages of laptop computers outweigh desktop computers in most categories [1]. Since laptops are also used for leisure purposes, and the recent increase in working or studying from home, the trend towards using more laptops instead of traditional desktop computers, is believed to continue [2]. 
MSDs are a common problem among office workers, causing decreased work ability, increased sick leave, and long-term disability [3]. MSDs among office workers are often associated with awkward postures, static load, bad ergonomics, and low physical activity $[4,5,6]$. Several authors have discussed ergonomic concerns in laptop users, such as difficulty keeping a neutral posture, not using an ergonomically appropriate workstation, and adjustability restrictions due to its specific design [7, 8, 9]. In contrast to previously mentioned ergonomic concerns, working with a laptop can provide more variability in posture, and locations of work. Postural variability and working in different settings might have a positive impact on work-time physical activity and reducing MSDs [10]. The most common types of MSDs among laptop users are shoulder pain, neck pain, low back pain, wrist pain, and finger pain [11]. The prevalence of MSDs in these body regions is similar to the results of studies investigating the prevalence of MSDs among office workers without addressing which type of equipment was used for work $[12,13]$. In this study we investigate the prevalence of MSDs separately, depending on the type of computer used for work, to better determine if any difference is present.

A laptop computer can be used in different positions and configurations. Studies have investigated discomfort and muscle activity in different body positions and laptop configurations. When changing the position of work or the physical configuration of the laptop, muscle activity and discomfort seem to shift to different areas, therefore, making it impossible to find the best posture and setting to use the laptop [7, 14]. Laptop users have been shown to work in more extreme postures than desktop computer users, therefore causing postural strain. Postural strain is considered one of the factors leading to MSDs [8]. There is some evidence, that postural changes in the neck, forward-head posture, in particular, are associated with changes in functional characteristics, like lower MVC force of neck extensor muscles [15], and reduced range of flexion in the neck [16]. It is also known, that neck pain is associated with changes in functional characteristics, such as reduced neck AROM [17], MVC force [18], JPE [19], and PPT in certain neck and shoulder areas [20]. The differences in neck posture between laptop and desktop computer users have been recorded [21], however, the differences in functional characteristics of the neck are unknown.

The aim of this study was to compare the prevalence of upper body MSDs and functional characteristics of the neck among office workers using a laptop or desktop computer for work. More specifically, AROM, MVC force, JPE, and PPT were measured as functional characteristics. Since using a laptop can cause more awkward postures $[7,8,9]$, and awkward postures are associated with a higher postural strain resulting in MSDs [8], together with negative changes in functional characteristics of the neck [15, 16], we hypothesized, that laptop users have more neck and shoulder area MSDs and impairments of functional characteristics of the neck when compared with workers using a desktop computer.

\section{Materials \& Methods}

Subjects 
A total of 110 office workers ( $80.9 \%$ female) with an age range of $23-60$ years (mean $40.97 \pm 9.96$ years) participated in this study. Based on the type of computer used for work, the subjects were divided into two groups: laptop users $(n=45)$ and desktop computer users $(n=65)$ as a control group. The work-related data, demographic information, and physical activity are presented in Table 1 . There were no statistically significant differences between the groups based on this data. The inclusion criteria were working in an office setting, working with a computer for at least 6 hours a day, and age between 20-60 years. The inclusion criteria for the laptop group was using a laptop-type computer for work without an external display, keyboard, or mouse. The exclusion criteria were chronic neurological, orthopedic, metabolic, or inflammatory conditions, legally designated disability, and body mass index (BMI) over $30 \mathrm{~kg} / \mathrm{m}^{2}$. The participants were recruited from five different organizations by contacting their health and safety officer. The study took place at the participants' workplace in a private room adjusted for this study. Participation in this study was voluntary, all the participants signed the informed consent form. This study was approved by the Ethics Review Committee on Human Research, University of Tartu. (Report nr 287/T-26)

Study design

The data collection consisted of two parts. First, filling the questionnaires for determining eligibility for participation and assessing the prevalence of MSDs. The second part consisted of measuring height, body weight, AROM and JPE of the neck, MVC force of the neck muscles, and soft tissue PPT of the neck and shoulder region.

The eligibility for participation was assessed using a Pre-Test questionnaire, which inquired about the prevalence of different chronic health conditions. We measured self-reported physical activity, body mass index, and physical demands of the work to assess the homogeneity regarding lifestyle and physical work demands, of the two groups. Baecke Physical Activity Questionnaire was used to measure the selfreported overall physical activity and work-related physical activity. The comparison of demographic and work-related characteristics between the groups is presented in Table 1. 
Table 1

Demographic and work-related characteristics of the subjects based on the type of computer used for work (mean \pm SD).

\begin{tabular}{|llll|}
\hline Feature & Desktop users $(\mathbf{n}=\mathbf{6 5})$ & Laptop users $(\mathbf{n}=\mathbf{4 5})$ & p-value $(95 \% \mathrm{Cl})$ \\
\hline Age & $41.78 \pm 9.99$ & $39.89 \pm 10.11$ & $0.33(-1.98$ to 5.77$)$ \\
\hline Female $(\%)$ & $86.2 \%$ & $73.3 \%$ & 0.09 \\
\hline BMI $\left(\mathrm{kg} / \mathrm{m}^{2}\right)$ & $24.30 \pm 3.25$ & $23.98 \pm 3.43$ & $0.63(-0.97$ to 1.62$)$ \\
\hline Right handed $(\%)$ & $97.1 \%$ & $93.3 \%$ & 0.37 \\
\hline Work experience (years) & $16.04 \pm 9.97$ & $15.16 \pm 10.74$ & $0.56(-3.14$ to 4.90$)$ \\
\hline EICS & $8.05 \pm 8.45$ & $5.79 \pm 7.55$ & $0.15(-0.79$ to 5.31$)$ \\
\hline BPAl & $8.12 \pm 1.38$ & $7.72 \pm 1.47$ & $0.15(-0.15$ to 0.95$)$ \\
\hline BPAl work & $1.95 \pm 0.31$ & $2.00 \pm 0.35$ & $0.51(-0.17$ to 0.09$)$ \\
\hline Screen time at work (hrs) & $7.74 \pm 1.16$ & $7.72 \pm 1.75$ & $0.88(-0.58$ to 0.61$)$ \\
\hline BMI - body mass index; EICS - experience in current settings; BPAI - Baecke Physical Activity Index. \\
\hline
\end{tabular}

Order of procedures:

1. The research methods were introduced to the participants, and informed consent was signed.

2. The suitability for this study was assessed using the Pre-Test questionnaire.

3. Body height and weight were measured, and BMI was calculated.

4. Subjects filled in the Baecke Physical Activity Questionnaire, and the Nordic Musculoskeletal Questionnaire.

5. AROM of the neck was measured.

6. JPE of the neck was measured.

7. MVC force of the neck muscles was measured.

8. PPT of the soft tissues in the neck and shoulder region was measured.

Evaluation of MSD prevalence

Nordic Musculoskeletal Questionnaire was used to determine the prevalence and duration of MSDs in different body regions. In this study, the answering options of the Nordic questionnaire were reduced to the neck, left shoulder, right shoulder, upper back, lower back, left elbow-wrist-hand (EWH), and right EWH. We decided not to include recording lower-body MSDs, since they are not as much affected by the type of computer used for work, therefore less relevant considering the aim of this study. The duration of MSDs was recorded as pain currently, pain in the previous 7 days, and pain in the previous 6 months.

Measurements of functional characteristics 
During the measurements of functional characteristics of the neck- and shoulder region, the subject was sitting on an adjustable piano bench, with 90 degrees of flexion in the hip and knee joints, and feet fully supported on the ground. The participants were asked to keep their natural posture and support their forearms on their thighs.

The AROM of the neck was measured using a CROM goniometer (Performance Attainment Associates, USA). Flexion, extension, lateral flexion, and rotation to both sides were measured. The reading was recorded when the participants reached their maximal range, perceived pain, or started to compensate with their trunks. Every function was measured three times and the arithmetical mean was calculated.

The JPE was measured using a laser-pointer mounted to the midline, on the CROM goniometer. The JPE target was attached to the eye level, on the wall $90 \mathrm{~cm}$ in front of the subject. The participants were asked to point the laser in the middle of the target, close their eyes, rotate the head to the side, as far as possible, and return to the middle without opening the eyes. The final point was measured from the center of the target. JPE was measured six times on both sides, and the arithmetical mean was calculated.

The MVC force of neck muscles was measured using a hand-held digital dynamometer Lafayette Manual Muscle Testing System (Lafayette Instrument Company, USA). We measured the MVC force in protraction, extension, and lateral flexion to left and right. The unit of measurement for MVC force was kilograms $(\mathrm{kg})$. The participants were asked not to compensate with their trunk or limbs by keeping them in place and using only the neck. Depending on the direction measured, the dynamometer was held by the researcher against the participant's forehead, temporal region, or occipital region. The participants were asked to push their heads against the dynamometer as hard as they could for five seconds straight, while the researcher kept the dynamometer in place. Every direction was measured three times, with 60 seconds of rest between the repetitions. The best of three repetitions was used in statistical analysis.

PPT of the subjects was measured using a handheld digital algometer with a rubber disk area of $1 \mathrm{~cm}^{2}$. PPT provides a quantitative measurement of sensory perception of mechanical stimuli. To assess the PPT, the rubber disk of the algometer was applied perpendicularly against the skin on the test area, and the pressure was applied at the rate of approximately $50 \mathrm{kPa} / \mathrm{s}$. PPT was defined as the pressure $(\mathrm{kPa})$ where the pain was first experienced. The subjects were instructed to push a button, when they reached the PPT, locking the exact value on the display of the algometer. We included three test sites on both body sides. The first site was the midpoint of the upper trapezius, measured from the spinous process of $\mathrm{C} 7$ to acromion. The second site was the inferior end of the levator scapulae muscle near the superior angle of the scapula. The third point of measurement was the midpoint of neck extensor muscles, measured from the base of the neck to the base of the skull. The assessment consisted of three sets of measurements 5 minutes apart. The mean PPT was included in statistical analysis. All measurements were carried out by a licensed physiotherapist.

\section{Statistical analysis}


The prevalence of MSDs is presented as percentages. To determine the statistically significant differences in the prevalence of MSDs between the groups, the Chi-square test was used. Odds ratios were used to express the magnitude of the difference among statistically significant results. The functional characteristics of the groups are presented as mean \pm SD. Normality was determined using the Shapiro-Wilks test. Depending on the distribution, the Welch t-test or Mann-Whitney u-test was used to determine the statistical significance when comparing the means of functional characteristics between the groups. 95\% confidence intervals were included in the comparison of functional characteristics. Data analysis for MVC force and PPT was done separately for both genders. Multivariate logistic regression analysis was used to find associations between NSP, type of computer used for work, and functional characteristics of the neck and shoulder region. For the regression analysis, we used total AROM, total MVC force, total JPE, and total PPT, where the results of directions/locations of individual characteristics were merged. This merged model was used to reduce correlations between covariates for a better fit. The results of this analysis are presented as odds ratios and $95 \%$ confidence intervals.

\section{Results}

Figure 1 represents the prevalence of MSDs in different body areas among office workers working with a laptop or desktop computer. The results indicate a higher prevalence of neck and shoulder region MSDs among workers using a laptop when compared with the control group. The difference was significant particularly in the shoulder area, whereas the overall neck and shoulder MSD prevalence was slightly higher among laptop users, but did not reach statistical significance. Laptop users demonstrated a statistically significantly higher prevalence of right shoulder pain on the day of participation $(p=1 \mathrm{E}-175$, $O R=4.47)$, in the previous 7 days $(p=0.008, O R=3.74)$, and the previous 6 months $(p=0.002, O R=3.57)$, when compared with desktop computer users. Laptop users also had a statistically significantly higher prevalence of left shoulder pain in the previous 7 days $(p=0.04, O R=2.44)$ when compared with desktop computer users. Desktop computer users had a statistically significantly higher prevalence of lower back pain in the previous 6 months $(p=0.05, O R=2.24)$ when compared with laptop users.

Our analysis of the functional characteristics of the neck indicated no statistically significant differences between the groups. We found no statistically significant differences in AROM of the neck, nor in neck JPE between laptop and desktop computer users. (Table 2) 
Table 2

Active range of motion and joint position error of the neck in desktop users and laptop users (mean $\pm \mathrm{SD})$.

\begin{tabular}{|lllll|}
\hline Function & Desktop users $(n=65)$ & Laptop users $(n=45)$ & p-value & $95 \%$ Cl \\
\hline Flexion & $57.30 \pm 9.43$ & $56.58 \pm 10.38$ & 0.71 & -3.13 to 4.57 \\
\hline Extension & $70.15 \pm 14.58$ & $72.81 \pm 11.13$ & 0.28 & -7.52 to 2.21 \\
\hline Left LF & $50.07 \pm 10.26$ & $52.12 \pm 10.16$ & 0.30 & -5.97 to 1.88 \\
\hline Right LF & $46.04 \pm 10.35$ & $46.55 \pm 10.72$ & 0.80 & -4.58 to 3.56 \\
\hline Left rotation & $68.67 \pm 9.31$ & $70.92 \pm 9.26$ & 0.27 & -5.82 to 1.32 \\
\hline Right rotation & $68.19 \pm 8.55$ & $70.20 \pm 9.91$ & 0.27 & -5.63 to 1.60 \\
\hline Left rotation JPE & $51.67 \pm 20.79$ & $46.61 \pm 13.30$ & 0.30 & -1.39 to 11.51 \\
\hline Right rotation JPE & $53.08 \pm 14.59$ & $49.64 \pm 14.88$ & 0.25 & -2.25 to 9.11 \\
\hline LF - lateral flexion; JPE - joint position error. & & & \\
\hline
\end{tabular}

There were no statistically significant differences in MVC force of the neck muscles when laptop users were compared with desktop computer users of the same gender. (Table 3) 
Table 3

Maximal voluntary contraction force of the neck muscles in office workers based on the type of computer used for work (mean \pm SD).

\begin{tabular}{|c|c|c|c|c|}
\hline Function & $\begin{array}{l}\text { Desktop users ( } n=65,86 \% \\
\text { females) }\end{array}$ & $\begin{array}{l}\text { Laptop users ( } n=45,73 \% \\
\text { females) }\end{array}$ & $\begin{array}{l}\mathrm{p}- \\
\text { value }\end{array}$ & $95 \% \mathrm{Cl}$ \\
\hline Protraction & $8.46 \pm 8.76$ & $7.61 \pm 2.14$ & 0.60 & -1.60 to \\
\hline $\begin{array}{l}\text { Female } \\
\text { Male }\end{array}$ & $11.44 \pm 4.29$ & $11.49 \pm 3.38$ & 0.98 & $\begin{array}{l}-3.74 \text { to } \\
3.65\end{array}$ \\
\hline Extension & $9.02 \pm 2.77$ & $9.59 \pm 2.74$ & 0.34 & -1.76 to \\
\hline $\begin{array}{l}\text { Female } \\
\text { Male }\end{array}$ & $10.84 \pm 3.67$ & $12.97 \pm 2.83$ & 0.17 & $\begin{array}{l}-5.27 \text { to } \\
1.02\end{array}$ \\
\hline Left LF & $6.55 \pm 1.77$ & $6.95 \pm 2.10$ & 0.62 & $\begin{array}{c}-1.26 \text { to } \\
0.47\end{array}$ \\
\hline $\begin{array}{l}\text { Female } \\
\text { Male }\end{array}$ & $9.60 \pm 3.26$ & $10.38 \pm 3.06$ & 0.59 & $\begin{array}{l}-3.73 \text { to } \\
2.18\end{array}$ \\
\hline Right LF & $6.23 \pm 1.89$ & $6.81 \pm 1.94$ & 0.23 & $\begin{array}{l}-1.42 \text { to } \\
0.26\end{array}$ \\
\hline $\begin{array}{l}\text { Female } \\
\text { Male }\end{array}$ & $8.89 \pm 2.76$ & $10.33 \pm 3.52$ & 0.31 & $\begin{array}{l}-4.32 \text { to } \\
1.43\end{array}$ \\
\hline
\end{tabular}

Laptop users did not present any statistically significant differences in the PPT of the muscles in the neck and shoulder area when compared with desktop computer users of the same gender. (Table 4) 
Table 4

Pain-pressure threshold of different neck and shoulder regions among office workers based on the type of computer used for work (mean $\pm \mathrm{SD}$ ).

\begin{tabular}{|c|c|c|c|c|}
\hline Location & $\begin{array}{l}\text { Desktop users ( } n=65,86 \% \\
\text { females) }\end{array}$ & $\begin{array}{l}\text { Laptop users ( } n=43,72 \% \\
\text { females) }\end{array}$ & $\begin{array}{l}\mathrm{p}- \\
\text { value }\end{array}$ & $95 \% \mathrm{Cl}$ \\
\hline Left UT & $6.99 \pm 2.61$ & $6.99 \pm 3.40$ & 0.68 & -1.41 to \\
\hline $\begin{array}{l}\text { Female } \\
\text { Male }\end{array}$ & $8.86 \pm 6.35$ & $6.37 \pm 2.62$ & 0.72 & $\begin{array}{l}-2.52 \text { to } \\
7.48\end{array}$ \\
\hline Right UT & $6.90 \pm 2.56$ & $6.68 \pm 3.94$ & 0.25 & -1.37 to \\
\hline $\begin{array}{l}\text { Female } \\
\text { Male }\end{array}$ & $8.79 \pm 7.28$ & $6.94 \pm 2.32$ & 0.97 & $\begin{array}{l}-3.82 \text { to } \\
7.53\end{array}$ \\
\hline Left LS & $8.62 \pm 3.72$ & $8.05 \pm 3.63$ & 0.44 & -1.06 to \\
\hline $\begin{array}{l}\text { Female } \\
\text { Male }\end{array}$ & $9.79 \pm 8.16$ & $7.86 \pm 4.55$ & 0.97 & $\begin{array}{l}-4.67 \text { to } \\
8.53\end{array}$ \\
\hline Right LS & $8.25 \pm 3.68$ & $8.13 \pm 3.40$ & 0.94 & $\begin{array}{l}-1.44 \text { to } \\
1.69\end{array}$ \\
\hline $\begin{array}{l}\text { Female } \\
\text { Male }\end{array}$ & $8.81 \pm 7.42$ & $7.52 \pm 4.22$ & 0.81 & $\begin{array}{l}-4.73 \text { to } \\
7.30\end{array}$ \\
\hline Left NE & $3.77 \pm 1.70$ & $3.75 \pm 1.39$ & 0.76 & -0.65 to \\
\hline $\begin{array}{l}\text { Female } \\
\text { Male }\end{array}$ & $3.38 \pm 2.61$ & $3.15 \pm 1.83$ & 0.81 & $\begin{array}{l}-1.95 \text { to } \\
2.43\end{array}$ \\
\hline Right NE & $3.64 \pm 1.61$ & $3.76 \pm 1.55$ & 0.69 & $\begin{array}{l}-0.83 \text { to } \\
0.58\end{array}$ \\
\hline $\begin{array}{l}\text { Female } \\
\text { Male }\end{array}$ & $3.37 \pm 2.39$ & $3.33 \pm 1.91$ & 0.91 & $\begin{array}{l}-2.03 \text { to } \\
2.11\end{array}$ \\
\hline
\end{tabular}

Table 5 shows the results of the binary logistic regression analysis, investigating the associations between neck and shoulder pain, using a laptop for work, and functional characteristics of the neck. The models presented a good fit with the area under the ROC curve (AUC) of 0.67-0.73. The analysis suggested statistically significant associations between the acute neck and shoulder pain and AROM of the neck, however, the odds ratios were indicating an irrelevant effect size for these associations. 
Table 5

Logistic regression model for neck and shoulder pain with different duration in office workers $(n=110$, $80.1 \%$ females).

\begin{tabular}{|c|c|c|c|c|c|c|}
\hline \multirow[t]{2}{*}{ Factor } & \multicolumn{2}{|c|}{ NSP at the moment } & \multicolumn{2}{|c|}{ NSP in previous 7 days } & \multicolumn{2}{|c|}{ NSP in previous 6 months } \\
\hline & OR & $95 \% \mathrm{Cl}$ & OR & $95 \% \mathrm{Cl}$ & OR & $95 \% \mathrm{Cl}$ \\
\hline Laptop & 1.73 & 0.69 to 4.34 & 1.60 & 0.69 to 3.72 & 2.43 & 0.77 to 7.67 \\
\hline Total neck ROM & 0.98 & 0.97 to 0.99 & 0.99 & 0.98 to 1.00 & 1.00 & 0.98 to 1.01 \\
\hline Total neck Fmax & 1.00 & 0.97 to 1.04 & 1.02 & 0.99 to 1.06 & 0.99 & 0.95 to 1.03 \\
\hline Total neck JPE & 1.00 & 0.98 to 1.02 & 1.00 & 0.99 to 1.02 & 1.01 & 0.99 to 1.03 \\
\hline Total neck PPT & 0.98 & 0.95 to 1.01 & 1.00 & 0.98 to 1.03 & 1.01 & 0.98 to 1.05 \\
\hline
\end{tabular}

\section{Discussion}

The main findings of this study were:

1. Laptop users had a statistically significantly higher prevalence of MSDs in the shoulder area.

2. Desktop computer users had a statistically significantly higher prevalence of lower back pain in the previous 6 months.

3. The functional characteristics of the neck did not differ between laptop and desktop computer users.

In this study, we measured the prevalence of MSDs in the upper body and spine regions. The overall prevalence of MSDs in both groups was high with $98 \%$ of subjects in both groups experiencing MSDs in any body region in the previous 6 months. In the previous 7 days, $80 \%$ of laptop users and $78 \%$ of desktop computer users had experienced MSDs in any body region. These general results indicate, that the type of computer used for work does not determine the overall prevalence of MSDs and other factors must be considered.

Since one of the most important differences between using a laptop and a desktop computer is the position of the screen, and therefore the increased flexion of the neck [22], we hypothesized a higher prevalence of MSDs in the neck and shoulder region among laptop users. In the neck and shoulder region, we recorded MSDs in the neck, left, and right shoulder and calculated a total prevalence of neck and shoulder MSDs. In the NORDIC Musculoskeletal Questionnaire, the neck region was visualized from the base of the skull down to the $\mathrm{C} 6-\mathrm{C} 7$ height. The lateral part of the upper trapezius muscle was counted as the shoulder area. Despite the laptop group having a higher prevalence of MSDs in the neck area, the difference was not statistically significant. Previous research has indicated the weekly prevalence of neck pain among laptop users being over 70\% [23], however, in our subjects the weekly prevalence was only 
$44.4 \%$ and the $70 \%$ prevalence was reached when the previous 6 months were addressed. The difference between the studies can be explained by a different questionnaire used, since in our study we inquired about pain, not including slight discomfort. The statistically significantly higher prevalence of MSDs in the shoulders can be explained by a higher postural strain on the upper trapezius muscles caused by the forward head posture [24]. In addition to the forward head posture, using a laptop without an external keyboard can also cause awkward upper limb positions, such as elevated shoulders, therefore causing additional muscle activity in the upper trapezius muscles [25]. Considering this mechanism, our result of higher shoulder pain prevalence in the laptop group is supported by previous research, that has indicated prolonged upper trapezius activity as an associated factor of developing neck and shoulder pain [26]. When we added up neck and shoulder MSDs, the total prevalence was not statistically significant during the day of participation $(p=0.26)$, the past 7 days $(p=0.23)$, or the past 6 months $(p=0.15)$. This together with the prevalence of MSDs in the neck region not being significantly different, indicates working with a laptop computer causes more strain on the muscles in the shoulder area, rather than muscles in the mid- or upper neck.

In this study, the prevalence of low back pain in the previous 6 months was statistically significantly higher among desktop computer users (75\%) when compared with laptop users (58\%). In both groups, the overall prevalence was high and comparable with research on the prevalence of MSDs among office workers indicating a prevalence of over $50 \%[6,12]$. Two factors measured in this study can be considered contributing to the higher prevalence of LBP among the desktop computer group. The first might be a higher percentage of female workers in the desktop group. Several authors have documented, that females are at a greater risk of developing LBP $[27,28]$. In our study, the desktop group had $12.82 \%$ more female participants, which was not a statistically significant difference $(p=0.09)$, but also not perfectly desirable homogeneity. The second factor is daily time spent standing at work. The Laptop group demonstrated on average 16 minutes more time spent standing per workday, however, the difference between the groups was not statistically significant $(p=0.15)$. We investigated the total daily time spent standing, therefore we can't make conclusions about sitting and standing behavior, frequency of breaks, and positions of work. We can only make an assumption on previous research that using a laptop might increase postural variety, reducing static postures, therefore reducing the chance of developing LBP compared with working with a desktop computer [10].

There were no statistically significant differences between the desktop and laptop groups when the functional characteristics of the neck were compared. The AROM of the neck did not differ between the desktop and laptop groups. This indicates, that different neck posture from using a laptop is not a relevant factor for causing changes that might limit AROM. Since the neck position during work differs between desktop and laptop computer users, we measured the MVC force of the neck muscles to see how it affects the neck muscles' ability to generate force. From our data we conclude, that the type of computer used for work does not influence the force generation ability of the neck muscles. This finding is supported by the research by Ghamkhar \& Kahlaee (2019), who found, that forward head posture is not associated with altered muscle performance, pain, or disability [29]. Similar was our result of regression analysis, which also did not find an association between neck and shoulder pain and total isometric 
strength of the neck muscles (Table 5). The neck muscles' ability to generate force can be disturbed by the prevalence of chronic neck pain [30], but the laptop group did not experience more neck pain, in particular, instead, the pain was more prevalent in the shoulder region, therefore not compromising the neck's ability to generate force. While it is known, that JPE is altered in subjects experiencing pain [19], our result of no differences in neck JPE between the groups can indicate, that the position sense is not altered by the type of neck posture used for work, since the prevalence of neck pain was similar in both groups. Because there were significantly more MSDs in the shoulder areas among laptop users, the neck JPE test could be used with lateral flexion instead of rotation to induce more discomfort in the upper trapezius region while executing the test. Using lateral flexion might include more shoulder region influence on the outcomes of the test. We measured PPT as an indicator of pressure sensitivity of soft tissues in the neck and shoulder area. Working with a laptop in a seated position with increased neck flexion can cause more static muscle activity to the neck extensors and shoulder muscles [14], which can cause lowered PPT as a symptom of soft tissue overload [31]. Since the prevalence of acute shoulder area pain was higher among laptop users, we expected to find differences in PPT in the upper trapezius region. There were no statistically significant differences in any of the locations measured between laptop and desktop computer users. We believe this is due to most workers feeling neck and shoulder region discomfort mainly during working with a screen, which will be alleviated during breaks or leisure. Future studies should measure PPT during the work process to better assess the soft tissue sensitivity directly related to work.

This study has several limitations. The gender ratio of the groups was slightly different, which could have influenced the results of MSD prevalence since the female gender is considered a risk factor in developing some MSDs $[6,27]$. We analyzed the Fmax and PPT separately for male and female participants, but the number of male participants was too low to draw any conclusions from that data. When comparing the prevalence of MSDs, there were several body regions, that came close to reaching statistical significance. Future studies comparing the prevalence of MSDs between laptop and desktop computer users should include higher sample sizes for more statistical power. Another limitation is not including questions about in which setting the participants used the laptop because as a portable device, it can be used in many different settings and postures. Despite having investigated self-reported workrelated physical activity, we don't have data on how many breaks workers took or how often they moved. Future studies should investigate work-related physical activity between the users of different types of computers by using a more objective method, like accelerometry. We measured the functional characteristics of the neck but did not focus on the shoulder area. Since laptop users had a significantly higher prevalence of MSDs in the shoulder region, future studies investigating the functional characteristics should include the shoulder. For a better understanding of changes related to the type of computer used for work, we also recommend future research to monitor the functional characteristics, pain, and discomfort continually throughout the workday and recovery.

\section{Conclusion}


Office workers using a laptop for work had a higher prevalence of MSDs in both shoulders when compared with office workers using a desktop computer for work. The prevalence of MSDs in the neck area or the total prevalence of neck and shoulder MSDs did not differ between the groups. Workers using a desktop computer had a higher prevalence of MSDs in the low back during the previous 6 months when compared with workers using the laptop computer. There were no differences in the AROM, MVC force, JPE, or PPT of the neck between office workers using a laptop or desktop computer for work. According to our data and previous research, using a laptop for work might cause more MSDs in the neck and shoulder area, however, it might not have a long-term effect on the functional characteristics of the neck. For a better understanding of the impact of using a laptop for work, further studies should investigate the use of laptops continually through the work process and recovery.

\section{Abbreviations}

MSD- musculoskeletal disorder

AROM - active range of motion

MVC force - maximal voluntary contraction force

JPE - joint position error

PPT - pain-pressure threshold

\section{Declarations}

Ethics approval and consent to participate

This study was approved by the Ethics Review Committee on Human Research, University of Tartu. (Report nr 287/T-26) All participants signed an informed consent form before participation.

Consent for publication

Not applicable

Availability of data and materials

The dataset generated in this study is available in the repository dataDOI: http://dx.doi.org/10.23673/re288

Competing interests

The authors declare that they have no competing interests

Funding 
This study received no specific funding

Authors' contributions

Martin Argus - conceived the idea, designed the study, collected \& analyzed the data, drafted the manuscript.

Mati Pääsuke - advised on the methods and structuring of the draft, revised the manuscript.

Acknowledgments

Not applicable

\section{References}

1. Kay R, Lauricella S. Exploring the Benefits and Challenges of Using Laptop Computers in Higher Education Classrooms: A Formative Analysis. Canadian Journal of Learning and Technology. 2011 Apr 17;37:1-18.

2. Hough PA, Nel M. Postural risks and musculoskeletal discomfort of three preferred positions during laptop use amongst students. South African Journal of Occupational Therapy. 2017;47:3-8.

3. Bevan S. Economic impact of musculoskeletal disorders (MSDs) on work in Europe. Best Pract Res Clin Rheumatol. 2015 Jun;29(3):356-73.

4. da Costa BR, Vieira ER. Risk factors for work-related musculoskeletal disorders: A systematic review of recent longitudinal studies. Am J Ind Med. 2010 Mar;53(3):285-323.

5. Wu S, He L, Li J, Wang J, Wang S. Visual display terminal use increases the prevalence and risk of work-related musculoskeletal disorders among Chinese office workers: a cross-sectional study. J Occup Health. 2012;54(1):34-43.

6. Kaliniene G, Ustinaviciene R, Skemiene L, Vaiciulis V, Vasilavicius P. Associations between musculoskeletal pain and work-related factors among public service sector computer workers in Kaunas County, Lithuania. BMC Musculoskeletal Disorders. 2016 Oct;17(1):420.

7. Moffet $H$, Hagberg $M$, Hansson-Risberg $E$, Karlqvist L. Influence of laptop computer design and working position on physical exposure variables. Clin Biomech (Bristol, Avon). 2002 Jun;17(5):36875 .

8. Yu Z, James C, Edwards S, Snodgrass SJ. Differences in posture kinematics between using a tablet, a laptop, and a desktop computer in sitting and in standing. Work. 2018;61(2):257-66.

9. Sommerich $\mathrm{CM}$, Starr $\mathrm{H}$, Smith $\mathrm{CA}$, Shivers $\mathrm{C}$. Effects of notebook computer configuration and task on user biomechanics, productivity, and comfort. International Journal of Industrial Ergonomics. 2002 Jul 1;30(1):7-31.

10. Davis KG, Kotowski SE. Postural variability: an effective way to reduce musculoskeletal discomfort in office work. Hum Factors. 2014 Nov;56(7):1249-61. 
11. Obembe AO, Johnson OE, Tanimowo TO, Onigbinde AT, Emechete AA. Musculoskeletal pain among undergraduate laptop users in a Nigerian University. J Back Musculoskelet Rehabil. 2013;26(4):38995.

12. Collins JD, O'Sullivan LW. Musculoskeletal disorder prevalence and psychosocial risk exposures by age and gender in a cohort of office based employees in two academic institutions. International Journal of Industrial Ergonomics. 2015 01;46:85-97.

13. Noroozi M, Hajibabaei M, Saki A, Memari Z. Prevalence of Musculoskeletal Disorders Among Office Workers. Jundishapur Journal of Health Sciences. 2015 Jan;7.

14. Intolo P, Shalokhon B, Wongwech G, Wisiasut P, Nanthavanij S, Baxter DG. Analysis of neck and shoulder postures, and muscle activities relative to perceived pain during laptop computer use at a low-height table, sofa, and bed. Work. 2019;63(3):361-7.

15. Goodarzi F, Rahnama L, Karimi N, Baghi R, Jaberzadeh S. The Effects of Forward Head Posture on Neck Extensor Muscle Thickness: An Ultrasonographic Study. J Manipulative Physiol Ther. 2018 Jan;41(1):34-41.

16. Kim D-H, Kim C-J, Son S-M. Neck Pain in Adults with Forward Head Posture: Effects of Craniovertebral Angle and Cervical Range of Motion. Osong Public Health Res Perspect. 2018 Dec;9(6):309-13.

17. Stenneberg MS, Rood M, de Bie R, Schmitt MA, Cattrysse E, Scholten-Peeters GG. To What Degree Does Active Cervical Range of Motion Differ Between Patients With Neck Pain, Patients With Whiplash, and Those Without Neck Pain? A Systematic Review and Meta-Analysis. Arch Phys Med Rehabil. 2017 Jul;98(7):1407-34.

18. Ylinen J, Salo P, Nykänen M, Kautiainen H, Häkkinen A. Decreased isometric neck strength in women with chronic neck pain and the repeatability of neck strength measurements. Arch Phys Med Rehabil. 2004 Aug;85(8):1303-8.

19. de Vries J, Ischebeck BK, Voogt LP, van der Geest JN, Janssen M, Frens MA, et al. Joint position sense error in people with neck pain: A systematic review. Man Ther. 2015 Dec;20(6):736-44.

20. Nunes AMP, Moita JPAM, Espanha MMMR, Petersen KK, Arendt-Nielsen L. Pressure pain thresholds in office workers with chronic neck pain: A systematic review and meta-analysis. Pain Pract. 2021 Apr;7.

21. Straker L, Jones KJ, Miller J. A comparison of the postures assumed when using laptop computers and desktop computers. Appl Ergon. 1997 Aug;28(4):263-8.

22. Alyami H, Albarrati AM. Comparison of Spinal Angles in a Typing Task on a Laptop and a Desktop Computer: A Preliminary Study. Am J Occup Ther. 2016 Dec;70(6):7006350020p1-8.

23. Erdinc 0 . Upper extremity musculoskeletal discomfort among occupational notebook personal computer users: work interference, associations with risk factors and the use of notebook computer stand and docking station. Work. 2011;39(4):455-63.

24. Lee S, Lee Y, Chung Y. Effect of changes in head postures during use of laptops on muscle activity of the neck and trunk. Physical Therapy Rehabilitation Science. 2017 Mar 30;6:33-8. 
25. Lee R, James C, Edwards S, Snodgrass SJ. Posture during the use of electronic devices in people with chronic neck pain: A 3D motion analysis project. Work. 2021;68(2):491-505.

26. Hanvold T, Wærsted M, Mengshoel A, Bjertness E, Stigum H, Twisk J, et al. The effect of work-related sustained trapezius muscle activity on the development of neck and shoulder pain among young adults. Scandinavian journal of work, environment \& health. 2013 Mar;39.

27. Shiri R, Falah-Hassani K, Heliövaara M, Solovieva S, Amiri S, Lallukka T, et al. Risk Factors for Low Back Pain: A Population-Based Longitudinal Study. Arthritis Care Res (Hoboken). 2019 Feb;71(2):290-9.

28. Bailey A. Risk factors for low back pain in women: still more questions to be answered. Menopause. 2009 Feb;16(1):3-4.

29. Ghamkhar L, Kahlaee AH. Is forward head posture relevant to cervical muscles performance and neck pain? A case-control study. Braz J Phys Ther. 2019 Aug;23(4):346-54.

30. Rezasoltani A, Ali-Reza A, Khosro K-K, Abbass R. Preliminary study of neck muscle size and strength measurements in females with chronic non-specific neck pain and healthy control subjects. Man Ther. 2010 Aug; 15(4):400-3.

31. Rosenberg S, Sipko T. Effect of adopting sitting position on threshold of pain soft tissue in region thoracic and lumbar spine in asymptomatic persons. Pain. 2016;17(1):17-24.

\section{Figures}

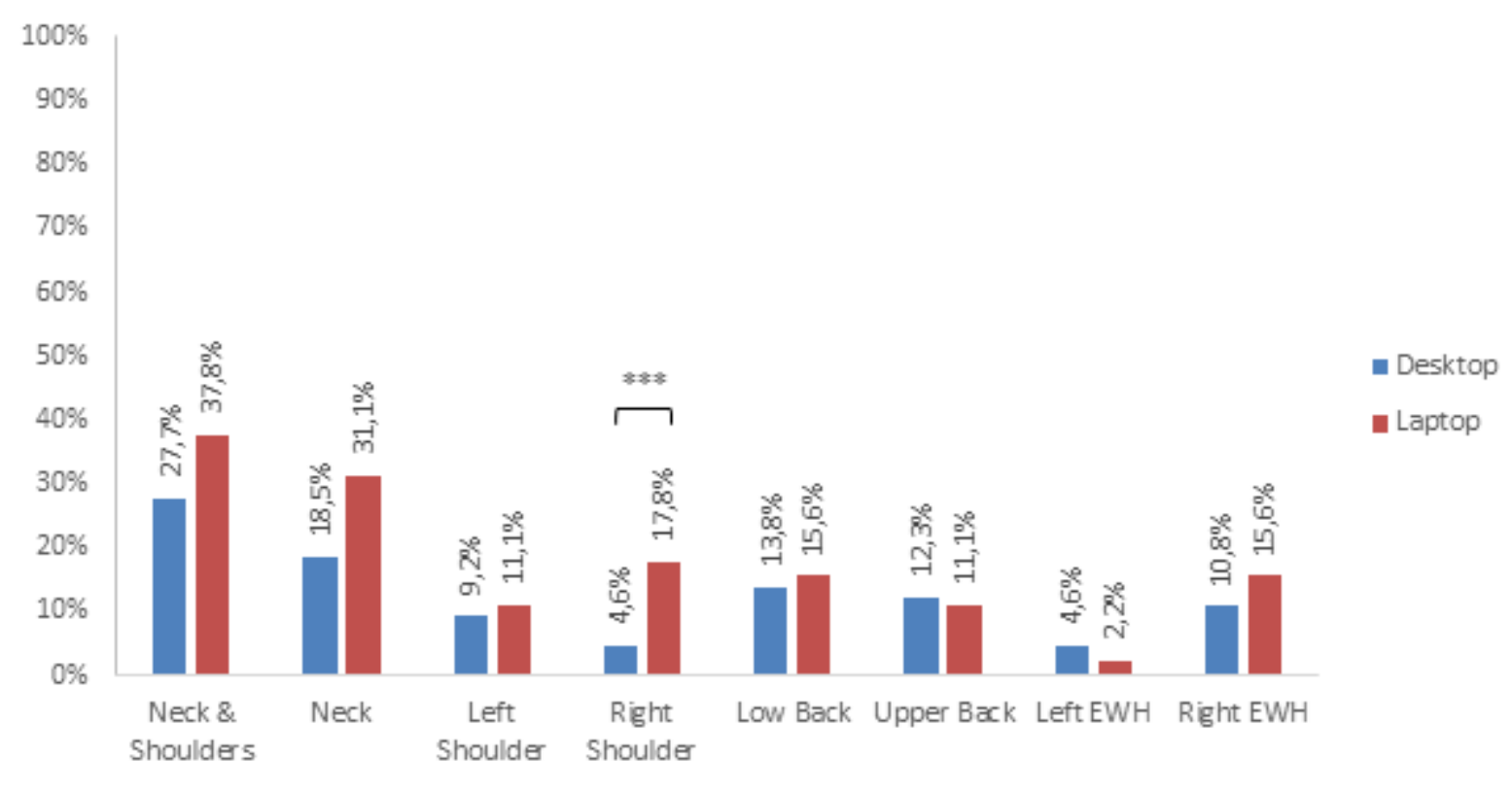


Prevalence of musculoskeletal disorders at the moment of answering among office workers working with a laptop $(n=45)$ or desktop $(n=65)$ computer. Legend: EWH - elbow, wrist, hand. *** - statistically significant $(p<0.001)$

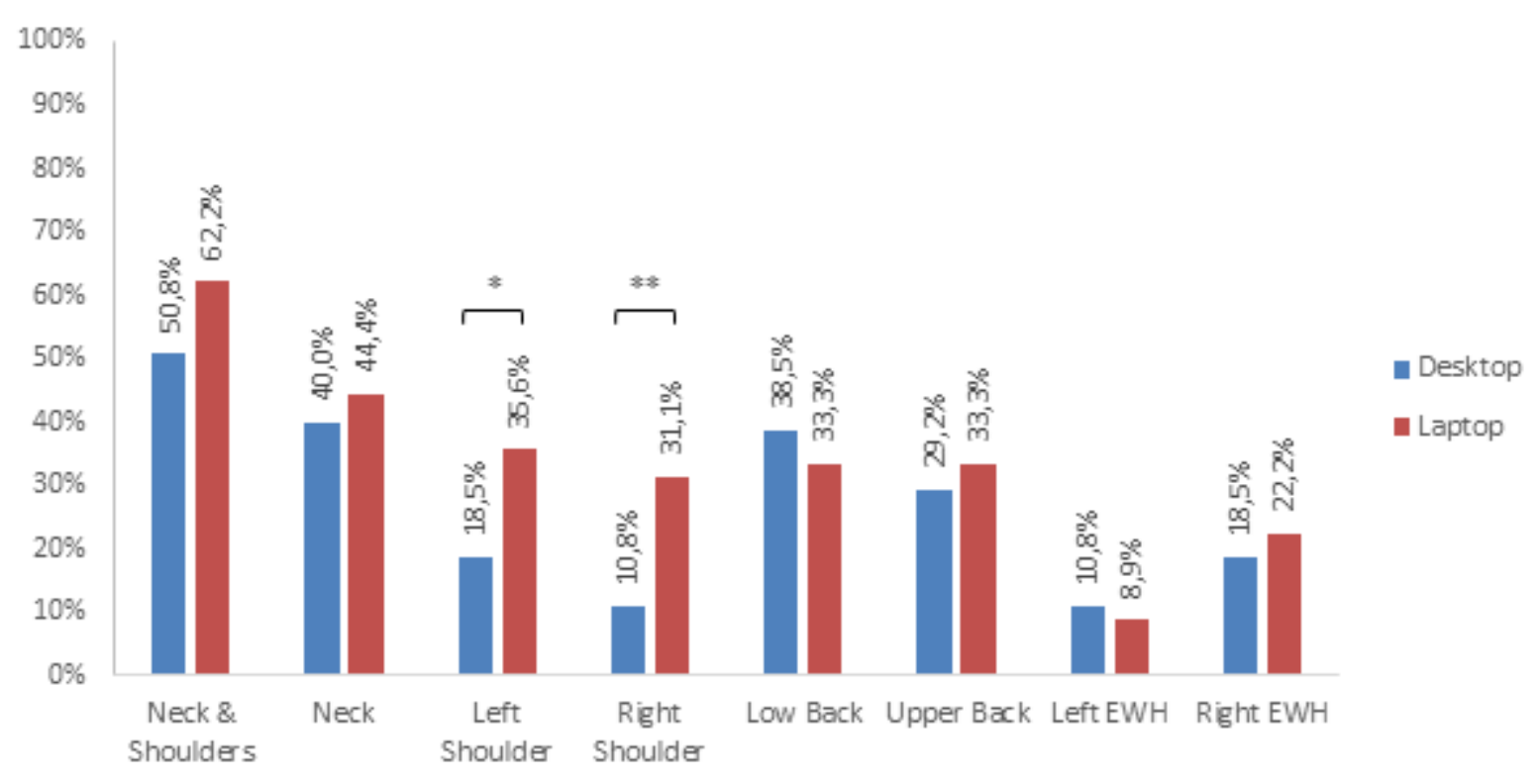

\section{Figure 2}

Prevalence of musculoskeletal disorders during the past 7 days among office workers working with a laptop $(n=45)$ or desktop $(n=65)$ computer. Legend: EWH - elbow, wrist, hand. * - statistically significant $(p<0.05) * \star$ - statistically significant $(p<0.01)$ 


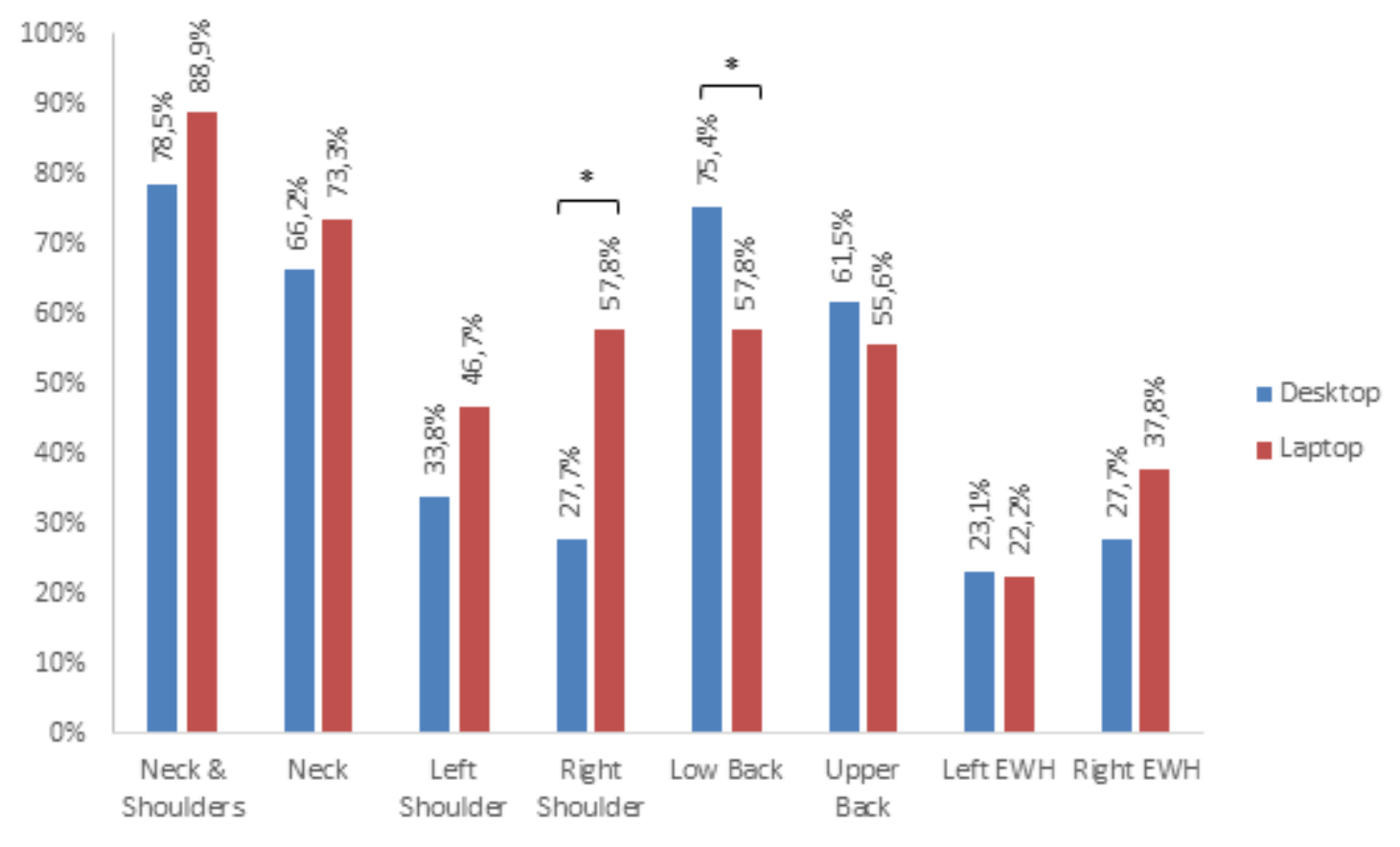

Figure 3

Prevalence of musculoskeletal disorders during the past 6 months among office workers working with a laptop $(n=45)$ or desktop $(n=65)$ computer. Legend: EWH - elbow, wrist, hand. * - statistically significant $(p<0.05) * \star$ - statistically significant $(p<0.01)$ 